\title{
ANALISIS INVESTASI PROYEK IT DALAM BINA NUSANTARA
}

\author{
Angellia Debora Suryawan \\ Information Systems Department, School of Information Systems, BINUS University \\ Jl. K.H. Syahdan No. 9, Palmerah, Jakarta Barat 11480 \\ asuryawan@binus.edu
}

\begin{abstract}
Companies should be able to adapt to the rapid development of IT. Therefore, IT is a must requirement for companies that want competent in today's business competition. The company must prepare budget that does not cheap for IT investment in order to meet global market competition. Companies need to really check and make sure that their IT investments will indeed be useful and profitable, or can obtain return of investment (ROI) at least. Companies also need to choose the right investments and in accordance with the company's business needs, so that IT can assist in improving corporate profits. This study aims to analyze utility of IT investment, IT investments in the budgeting process, and how the processes and methods of measurement and calculation of a good budgeting. Therefore, companies may prevent any losses on the IT investment. It is expected that through this study companies can decide whether the IT investment is feasible or not feasible to be implemented. Besides, companies can measure whether the investment will it be beneficial or detrimental.
\end{abstract}

Keywords: IT investment, Budget, Return of Investment (ROI)

\begin{abstract}
ABSTRAK
Perusahaan harus bisa beradaptasi dengan perkembangan IT yang sangat cepat. Karenanya IT merupakan kebutuhan wajib bagi perusahaan yang mau kompeten dalam persaingan bisnis sekarang ini. Perusahaan harus menyiapkan budget yang tidak sedikit dalam investasi di bidang IT guna memenuhi persaingan pasar secara global. Dalam investasi IT, perusahaan harus benar-benar mengecek dan memastikan bahwa investasi IT mereka memang akan berguna dan bisa menguntungkan bagi perusahaan, minimal bisa balik modal (Return of Investment). Perusahaan juga harus memilih investasi yang tepat dan sesuai dengan kebutuhan bisnis perusahaan, sehingga IT bisa membantu dalam meningkatkan laba perusahaan. Penelitian ini bertujuan untuk melakukan analisis manfaat investasi IT di Universitas Bina Nusantara, proses budgeting dalam investasi IT, serta bagaimana proses dan metode pengukuran dan perhitungan budget yang baik, agar perusahaan tidak mengalami kerugian dalam investasi IT. maka dari itu, diharapkan perusahaan bisa memutuskan apakah investasi IT tersebut layak diimplementasikan atau tidak. Selain itu perusahaan dapat menilai apakah investasi IT tersebut akan menguntungkan atau merugikan.
\end{abstract}

Kata kunci: Investasi IT, budget, Return of Investment 


\section{PENDAHULUAN}

Banyak CEO yang ragu dalam berinvestasi dibidang IT. Banyak analisis efektifitas dalam investasi IT yang hanya fokus pada evaluasi keuangan tradisional yang berdasarkan peningkatan keuntungan dan pengurangan biaya (Leem, Yoon, \& Park, 2004). Sementara para CEO pun tidak yakin investasi IT akan berguna kedepannya untuk perusahan dan takut investasi tersebut menjadi tidak berguna, dan tidak sesuai dengan ekspetasi perusahaan. Pengembalian modal (ROI) dalam investasi IT, bervariasi dengan signifikan diseluruh perusahaan, Standish Group melaporkan bahwa 15 persen dari seluruh investasi mereka ditinggalkan (tidak dilanjutkan), dan 50 persen lainya ditunda atau dikembalikan tanpa sesuai dengan ekpetasi user (Schwartz, 2004).

Ada beberapa masalah dan kesulitan dalam berinvestasi di bidang IT yang menyebabkan beban yang meningkat dan semakin lamanya waktu pengembalian modal. Berikut beberapa pertanyaan yang patut dipertimbangkan. Apakah nilai keuntungan IT sepadan dengan investasi yang dikeluarkan? Apakah sistem informasi global akan menolong perusahaan dalam meningkatkan kekuatan perusahaan dalam merencanakan dan mengimplementasikan strategi global? Bagaimana perusahaan menghitung nilai keberhasilan investasi IT dalam meningkatkan performa perusahaan? Pertanyaan-pertanyaan ini adalah masalah utama yang dipikirkan oleh para CIO dan manajer (Sakaguchi \& Dibrell, 1998).

Banyak hal yang harus diperhatikan dalam investasi dibidang IT, terutama memperhitungkan resiko yang akan dihadapi dan yang lebih penting memastikan bahwa budget yang dikeluarkan sudah se-efisien mungkin dan berapa lama waktu pengembalian modal dari budget yang dikeluarkan. Perusahaan harus benar-benar membuat analisis dan perencana yang matang dalam investasi tersebut.

Investasi dibidang IT tidak hanya berupa hardware dan software yang diperlukan perusahaan, tetapi juga memerlukan perangkat pendukung lainnya seperti LAN, jaringan, printer. Selain itu kemungkinan pengabaian biaya cukup tinggi, karena hanya memasukkan biaya hardware dan gaji, tanpa melihat biaya gangguan, training, dan resitensi pegawai (Maran, 2009). Padahal yang tidak kalah penting adalah sumber daya manusia, yang bisa mengerti, mengelola, dan mengoperasikan semua perangkat IT. Sehingga semua pendukung IT bisa berguna secara maksimal bagi perusahaan dan investasi yang dilakukan bisa optimal.

Keberhasilan tata kelola IT juga sangat menentukan dalam keberhasilan investasi IT. Tata kelola IT, menentukan ketepatan keputusan dalam perusahaan, karenanya tata kelola memainkan peranan penting dalam kinerja investasi IT (Gu, Xue, \& Ray, 2008). Perusahaan dengan tata kelola IT yang baik akan mendapatkan keuntungan maksimal dari investasi IT, sedangkan tata kelola IT yang buruk membuat perusahaan tidak mendapatkan manfaat dari investasi IT.

Universitas Bina Nusantara sangat memperhatikan kebutuhan IT dalam mendukung proses belajar mengajar, IT menjadi kelebihan dan kekuatan daya saing dalam menghadapi kompetitornya. Pimpinan Universitas Bina Nusantara sangat mendukung dalam investasi IT, mereka berani mengeluarkan investasi yang tidak sedikit dalam rangka memenuhi kebutuhan IT dan mengikuti perkembangan teknologi terbaru. Masalah yang ada pada saat ini adalah belum ada standarisasi terhadap proses anggaran dalam proses pengadaan investasi IT. Padahal diperlukan untuk menganalisis inventasi IT yang akan dilakukan, karena biaya yang dikeluarkan tidak sedikit, dan harus dicek dengan seksama agar bisa menghasilkan keuntungan yang optimal. Oleh sebab itu, pimpinan harus bisa menganalisis dan memastikan bahwa budget yang sudah dikeluarkan bisa efektif dan dimanfaatkan dengan maksimal, sehingga investasi IT menjadi berguna dalam meningkatkan profit perusahaan dan dapat mendukung proses operasional perusahaan. 


\section{METODE}

Pada studi kasus ini pengumpulan data diperoleh dari: (1) studi pustaka - dilakukan untuk mendapatkan teori-teori yang berhubungan dan mendukung penulisan pada studi kasus ini. Bahan studi pustaka didapan dari jurnal-jurnal, artikel, buku, maupun referensi lainnya yang membantu dalam proses pengolahan dan analisis data; (2) penelitian terdahulu - referensi untuk penulisan tesis ini, di mana dijelaskan apa saja yang menjadi latar belakang, perumusan masalah, batasan permasalahan, serta tujuan dan manfaat dari tesis ini, dan dijadikan acuan dalam mendapatkan informasi yang dibutuhkan.

\section{HASIL DAN PEMBAHASAN}

\section{Project Cost Management}

Menurut Kathy Schwalbe (2007, p266-267) Project cost management (manajemen biaya proyek) terdiri dari proses yang yang dibutuhkan untuk memastikan bahwa tim proyek menyelesaikan sebuah proyek dengan budget yang sudah disetujui.

Ada tiga proses dalam manajemen biaya proyek, yaitu: (1) cost estimating (perkiraan biaya), terdiri dari perkiraan atau penafsiran biaya dari resources yang dibutuhkan untuk menyelesaikan suatu proyek. Output utama dari proses perkiraan biaya adalah aktivitas perkiraan biaya dan mendukung detail, perubahan permintaan, dan perubahan rencana manajemen biaya; (2) cost budgeting (penganggaran biaya), terdiri dari alokasi seluruh perkiraan biaya kepada item pekerjaan individu untuk membuat dasar perhitungan performa. Output utama dari proses anggaran biaya adalah dasar biaya, pendanaan kebutuhan proyek, perubahan permintaan, dan perubahan rencana manajemen biaya; (3) cost Control (kontrol biaya), terdiri dari pengontrolan perubahan dari anggaran proyek. Output utama dari proses kontrol biaya adalah pengukuran performa, meramal informasi penyelesaian, perubahan permintaan, rekomendasi aksi perbaikan, perubahan rencana manajemen proyek (yang terdiri dari rencana manajemen biaya), perkiraan biaya, dasar biaya, dan aset proses organisasi.

\section{Cost Estimating (Perkiraan Biaya)}

Menurut Kathy Schwalbe (2007, p271-276), manajer proyek harus memperkirakan biaya dengan serius jika mereka ingin menyelesaikan proyek sesuai batasan anggaran. Setelah membuat daftar kebutuhan resource yang sesuai, manajer proyek dan tim proyek harus membangun beberapa perkiraan biaya untuk resource ini.

Ada tiga tipe dasar perkiraan biaya, yaitu: (1) rough order of magnitude (ROM) estimate yang menyediakan sebuah perkiraan dari apa yang akan menjadi garis besar biaya proyek. Perkiraan tipe ini selesai sangat awal dalam sebuah proyek atau bahkan sebelum proyek dimulai secara desmi. Manajer proyek dan top management menggunakan perkiraan ROM untuk menolong pembuatan keputusan dalam menyeleksi proyek. Rentang waktu untuk perkiraan tipe ini adalah biasanya tiga tahun atau lebih sebelum proyek selesai. Akurasi perkiraan ROM biasanya $-50 \%$ sampai $+100 \%$, artinya biaya proyek sebenarnya bisa menjadi 50\% dibawah perkiraan ROM atau 100\% diatas ROM; (2) budgetary estimate (perkiraan anggaran), digunakan untuk mengalokasikan uang kedalam anggaran organisasi. Perkiraan anggaran dibuat 1 sampai 2 tahun sebelum proyek selesai. Akurasi dari perkiraan anggaran biasanya $-10 \%$ sampai $+25 \%$, artinya biaya aktual dapat kurang dari $10 \%$ atau $25 \%$ lebih besar dari perkiraan anggaran; (3) definitive estimate (perkiraan pasti) yang menyediakan perkiraan akurat dari biaya proyek. A definitive estimate digunakan untuk membuat banyak keputusan purchasing yang 
mana membutuhkan perkiraan akurat dan untuk memperkirakan biaya akhir proyek. Definitive estimate dibuat 1 tahun atau kurang sebelum proyek selesai. A definitive estimate adalah tipe perkiraan yang paling akurat. Keakuratan tipe ini normalnya $-5 \%$ sampai $10 \%$, artinya biaya aktual dapat kurang dari $5 \%$ atau $10 \%$ lebih banyak dari definitive estimate.

Membuat perkiraan biaya adalah hal yang sulit, ada beberapa teknik dan tools yang umumnya sering digunakan: (1) analogous estimates, sering juga disebut top-dowm estimates, menggunakan biaya aktual sebelumnya, yaitu proyek yang sama sebagai dasar untuk perkiraan biaya dari proyek sekarang. Sebagai tambahan, kelompok yang menyiapkan perkiraan biaya harus mempunyai keahlian dalam menentukan bagian tepat dari proyek yang kira-kira akan lebih atau kurang mahal dari proyek yang sejalan. Tetapi, jika proyek yang diperkirakan terdiri dari bahasa pemrograman yang baru atau dikerjakan dengan tipe baru hardware dan network, teknik the analogous estimates dapat dengan mudah menghasilkan perkiraan yang terlalu lemah; (2) bottom-up estimates terdiri dari perkiraan item pekerjaan atau aktivitas individu dan menjumlahkan (memasukkan) mereka kedalam total proyek. Kadang-kadang dikenal sebagai Biaya Berdasarkan Aktivitas. Ukuran dari item pekerjaan individu dan pengalaman adalah kemudi menuju perkiraan yang akurat. Kekurangan dari bottom-up estimates adalah biasanya butuh waktu yang intensif, karenanya mahal untuk dikembangkan; (3) parametric modelling (pemodelan ukuran rata-rata) menggunakan karakteristik (parameter) proyek dalam model matematika untuk memperkirakan biaya proyek. Model parameter adalah lebih sulit yang biasanya terkomputerisasi.

Masalah-masalah khas perkiraan biaya dalam investasi IT: (1) perkiraan dilakukan terlalu cepat; (2) kurangnya pengalaman dalam memperkirakan biaya; (3) manusia yang condong kearah meremehkan; (4) manajemen menginginkan akurasi.

\section{Cost Control (Kontrol Biaya)}

Menurut Kathy Schwalbe (2007, p285-288), kontrol biaya proyek terdiri dari pengawasan kinerja biaya, memastikan bahwa hanya perubahan proyek yang sesuai yang dimasukkan kedalam revisi dasar biaya, dan menginformasikan kepada stakeholders tentang perubahan proyek yang akan mempengaruhi biaya proyek. Dasar biaya, laporan kinerja, permintaan perubahan, dan pendanaan kebutuhan proyek adalah input dalam proses control proyek. Output dari proses ini adalah perubahan rencana manajemen biaya, aksi pembetulan, revisi perkiraan untuk penyelesaian proyek, perubahan permintaan, dan perubahan proses asset organisasi, seperti dokumen pelajaran-pembelajaran.

Meskipun banyak pendekatan akuntansi umum yang tersedia untuk mengukur kinerja biaya, earned value management (EVM) adalah teknik kontrol biaya yang paling kuat yaitu unik dalam bidang manajemen proyek.

EVM adalah teknik pengukuran kinerja proyek yang mengintegrasikan lingkup, waktu, dan data biaya. EVM terdiri dari kalkulasi tiga nilai dari tiap aktivitas atau rangkuman aktivitas dari proyek: (1) planned value (PV), disebut juga anggaran, yaitu porsi dari rancangan perkiraan total biaya yang disetujui untuk dihabiskan dalam aktivitas selama periode yang diberikan; (2) actual cost (AC), yaitu total biaya langsung dan tidak langsung yang terjadi dalam aktivitas pencapaian kerja selama periode yang diberikan; (3) earned value (EV) (Tabel 1), yaitu perkiraan nilai dari kerja fisikal yang sebenarnya selesai. EV didasarkan pada perencanaan biaya awal untuk proyek atau aktivitas dan rate yang mana tim melengkapi pekerjaan proyek atau aktivitas pertanggal. The rate of performance (RP) adalah rasio dari pekerjaan actual yang selesai dengan persentase rencana kerja yang harus diselesaikan pada waktu tertentu selama proyek berlangsung atau aktivitas proyek.

Tabel 1 Earned Value Formulas (Kathy Schwalbe, 2007)

\begin{tabular}{lc}
\hline Term & Formula \\
\hline Earned Value & $\mathrm{EV}=$ PV to date X RP \\
\hline
\end{tabular}




\begin{tabular}{ll}
\hline Cost Variance & $\mathrm{CV}=\mathrm{EV}-\mathrm{AC}$ \\
\hline Schedule Variance & $\mathrm{SV}=\mathrm{EV}-\mathrm{PV}$ \\
\hline Cost Performance Index & $\mathrm{CPI}=\mathrm{EV} / \mathrm{PV}$ \\
\hline $\begin{array}{l}\text { Schedule Performance } \\
\text { Index }\end{array}$ & $\mathrm{SPI}=\mathrm{EV} / \mathrm{PV}$ \\
\hline $\begin{array}{l}\text { Estimate at Completion } \\
\text { (EAC) }\end{array}$ & $\mathrm{EAC}=\mathrm{BAC} / \mathrm{CPI}$ \\
\hline $\begin{array}{l}\text { Estimated Time to } \\
\text { Complete }\end{array}$ & $\begin{array}{l}\text { Original Time } \\
\text { Estimate/SPI }\end{array}$ \\
\hline
\end{tabular}

Cost variance (CV) adalah nilai minus yang didapatkan dari biaya actual. Schedule variance (SV) adalah nilai minus yang didapatkan dari nilai yang direncanakan. Cost performance index (CPI) adalah rasio nilai yang didapatkan dengan biaya aktual dan dapat digunakan untuk merancang perkiraan biaya sampai proyek selesai. Schedule performance index (SPI) adalah rasio nilai yang didapatkan dengan nilai yang direncanakan dan dapat digunakan untuk merancang perkiraan waktu untuk sampai proyek selesai. Estimate at completion (EAC) adalah perkiraan dari apa yang akan menjadi biaya untuk menyelesaikan dasar suatu proyek dalam kinerja tanggal. Budget at completion (BAC), yaitu total anggaran awal dari suatu proyek.

\section{IT di Universitas Bina Nusantara}

Universitas BINUS pertama kali adalah sebuah lembaga les komputer, Kursus Komputer Modern dibentuk pada tanggal 21 Oktober 1974. BINUS telah bertumbuh dan berkembang dengan sangat cepat, disertai dengan fondasi yang kuat, visi yang jelas, dan dedikasi yang tinggi. Pada 8 Agustus 1996, BINUS university disahkan. Dan pada 20 Desember 1998, STMIK Bina Nusantara bergabung dengan BINUS university, saat iu ada 6 fakultas: Ilmu Komputer, Bisnis dan Ekonomi, Teknologi dan Ilmu Pengetahuan, Budaya dan Bahasa, Psikologi, dan Multimedia dan Komunikasi.

BINUS berkembang dengan pesat dan sudah diperhitungkan peranannya dalam dunia pendidikan. Saat ini semua orang sudah mengenal BINUS, bahkan namanya sudah dikenal sampai kedaerah-daerah. Hal ini terjadi karena BINUS terus berusaha memperhatikan kebutuhan pelanggannya dan terus menganalisis kebutuhan terbaru yang diperlukan, serta terus berinovasi dengan menciptakan pembelajaran yang efektif dan canggih dengan dukungan dari sistem IT. BINUS menyadari bahwa perkembangan teknologi terus berubah dan berkembang, karenanya BINUS terus mengedepankan IT yang mendukung semua proses operasional BINUS.

Dalam mendukung proses belajar-mengajar di BINUS, disediakan aplikasi BINUSmaya, di mana semua dosen dan mahasiswa bisa mengakses materi, tugas, course outline, syllabus, dan berdiskusi. Selain itu terdapat aplikasi pendukung proses back-end, seperti aplikasi dilayanan mahasiswa, aplikasi penjadwalan, aplikasi admisi, aplikasi operasi akademik, aplikasi intern pegawai, dan sebagainya.

Selain itu BINUS juga didukung dengan sistem jaringan dan data center yang terorganisir baik dan canggih. Sebagai penyalur dan penghubung informasi BINUS menggunakan internet, intranet, VPN, dan fiber optic. Data Center Bina Nusantara meliputi layanan Data Center Room dan Computer Technical Support, and Maintenance. Data Center Room Bina Nusantara menempati ruangan seluas kurang lebih $50 \mathrm{~m} 2$ dilengkapi dengan raised floor dan dua AC Precision, rak server, tabung pemadam kebakaran dan dua buah UPS. Setiap Server yang ada di Data Center Room ditempatkan dalam rak dan dilengkapi dengan KVM Switch untuk pengoperasiannya. Dalam pengoperasiannya hanya staff tertentu yang bisa memasuki ruang data center dengan menggunakan access key (RFID) untuk keamanan ruang data center tersebut. Data center Bina Nusantara juga memberikan beberapa layanan baik secara internal maupun secara eksternal. 
Karena banyaknya aplikasi yang beredar di BINUS, investasi BINUS dalam IT tidaklah sedikit. Namun pimpinan BINUS amat mendukung investasi IT, karena IT merupakan keunggulan BINUS dalam bersaing dengan kompetitornya, dan saat ini BINUS adalah universitas yang paling canggih dalam proses belajar dan mengajarnya, tentu saja dengan dukungan tenaga IT professional dan alat (software dan hardware) yang canggih. IT juga digunakan oleh jajaran management dalam proses pengambilan keputusan dan strategi perusahaan kedepannya.

\section{Tata Kelola IT di Universitas Bina Nusantara}

Dalam mengelola system IT di BINUS dibentuk satu unit khusus, yaitu Information Technology Directorate. Salah satu kekuatan dasar BINUS adalah membuat dan mengoperasikan aktivitas akademik dan mendukung stakeholder grup BINUS adalah implementasi IT di setiap aspek akademik dan mendukung proses akademik. Direktorat IT tidak hanya bertanggung jawab untuk mendukung universitas BINUS, tetapi juga semua unit bisnis grup Bina Nusantara. Direktorat IT dipimpin oleh Eddy Santosa Jaya, S.Kom., MM.

Direktorat IT mempunyai lima fungsi utama, yaitu: (1) IS Development, departemen ini bertanggung jawab untuk mengembangkan aplikasi dalam area: universitas BINUS, BINUS Business School, BINUS Consulting \& Training, BIS Simprug, BIS Serpong, BINUS Center, BINUS Square, Finance Directorate, Marketing Directorate, Strategic Planning \& Corporate Development Directorate, Widia Center of Excellence for Teaching and Learning, Talent Management Directorate, General Affair \& Legal Directorate dan Information Technology Directorate; (2) University IS Development, departemen ini bertanggung jawab untuk mengembangkan aplikasi di area: BINUS University, BINUS Business School dan BINUS Online Learning; (3) School IS Development, departemen ini bertanggung jawab untuk mengembangkan aplikasi di area: BINUS School Simprug, BINUS School Serpong and Libraries in BINUS Group; (3) Technology Development, departemen ini bertanggung jawab untuk meneliti teknologi yang ada saat ini yang dapat diimplemenasikan di grup BINUS, mengelola sumber daya manusia (Associate Member), dan sebagai media komunikasi antara Direktorat IT dengan user; (4) IT operation, departemen ini bertanggung jawab mendukung operasi IT di grup BINUS dan komunitas disekitarnya. Departemen ini terdiri dari Network and Communication dan Data Center.

Direktorat IT juga mendirikan Applied Technology Laboratory (ATL), dengan tujuan untuk meningkatkan BINUSIAN dengan menyediakan servis komputer dan IT. ATL juga menyediakan fasilitas dan memberikan mahasiswa kesempatan untuk magang dan menyusun proyek menggunakan teknologi terbaru.

\section{Penggunaan Model Bisnis dalam Menyusun Kasus Bisnis IT}

Dalam proses pembuatan proyek baru, para pemimpin harus menganalisis dan memutuskan apakah investasi mereka akan bermanfaat dan menguntungkan atau malah merugikan perusahaan? Para pemimpin BINUS untungnya tidak mempunyai "legacy" mindset sehingga mereka sangat terbuka dan mendukung terhadap perkembangan dan perubahan IT. Bahkan mengikuti perkembangan IT, dan melakukan penelitian kira-kira teknologi baru apa yang sesuai dan bisa diimplementasikan di BINUS, guna meningkatkan keefektifan, keefisienan, dan keuntungan perusahaan.

Untuk memastikan dalam menentukan dan memilih proyek IT, maka sebelum para pimpinan memutuskan apakah harus melakukan investasi atau tidak, bisa dibantu dengan melakukan analisis menggunakan model bisnis dalam menyusun kasus bisnis IT. Analisis dimulai dengan modal yang dimiliki perusahaan, yaitu strategi, kemampuan, dan nilai-nilai perusahaan. Kemudian dilakukan analisis melalui pertanyaan-pertanyaan berikut: 
“Dapatkah IT menumbuhkan pendapatan?” Melalui pertanyaan ini dianalisis apakah investasi IT bisa: (1) meningkatkan produktivitas, siklus waktu, dan efektifitas dari proses penghasilan pendapatan; (2) meningkatkan kinerja karyawan dalam menghasilkan pendapatan; (3) menilai kuantitas pengambilan keputusan yang meningkat; (4) meningkatkan kontribusi IT untuk pendapatan ketika biaya turun atau tetap; (5) menambah arus pendapatan baru dari pelanggan saat ini; (6) memungkinkan peningkatan produk, servis, dan solusi, dan meningkatkan kontribusi IT terhadap laba bersih melalui peluncuran proyek IT baru.

“Dapatkah IT digunakan untuk memberikan efisiensi pada asset?” Melalui pertanyaan ini dianalisis apakah investasi IT bisa: (1) menurunkan total biaya infrastruktur dan operasi yang dimiliki saat ini; (2) meningkatkan efisiensi asset (uang yang didapat dari hasil penjualan yang dihasilkan dibandingkan dengan uang aset IT); (3) menurunkan biaya infrastruktur dan operasi ITsebagai persentase pendapatan.

“Dapatkan IT menghemat biaya?” Melalui pertanyaan ini dianalisis investasi IT apakah bisa: (1) meningkatkan produktivitas, siklus waktu, dan efektifitas dari proses yang ada (bukan proses untuk menghasilkan pendapatan); (2) meningkatkan kinerja (bukan kinerja dalam menghasilkan pendapatan) karyawan; (3) mengurangi biaya operasi bisnis saat ini.

Diharapkan ketiga pertanyaan tersebut akan menghasilkan efisiensi modal dan pertumbuhan keuntungan. Sehingga menghasilkan keyakinan investor terhadap nilai pasar.

Dalam upaya menganalisis investasi IT apakah akan menghasilkan dan meningkatkan nilai pasar digunakan pertanyaan berkut:

"Dapatkah IT menumbuhkan pendapatan berkelanjutan?” Melalui pertanyaan ini dianalisis apakah investasi IT bisa: (1) meningkatkan pangsa pasar; (2) meningkatkan brand reputation dan awareness; (3) meningkatkan kesuksesan proses inovasi.

"Dapatkah IT mempunyai siklus yang baik pada produktifitas inovasi dan meningkatkan keuntungan?” Di BINUS sebelum perusahaan mengambil keputusan dalam investasi IT, dilakukan analisis agar bisa didapatkan keuntungan maksimal. Proses analisis dilakukan melalui pertanyaanpertanyaan Bussiness Case Fot IT seperti yang sudah dijelaskan diatas. Jika jawaban dari semua pertanyaan tersebut positif, maka investasi IT akan dilakukan, namun jika setelah dilakukan analisis melalui pertanyaan-pertanyaan tersebut hasilnya negatif sudah tentu proyek IT tidak akan dibuat. Selain itu dilakukan juga analisis terhadap pertanyaan: why this? why now? dan why you. Sehingga bisa didefiniskan tujuan dan sasaran utama dari proyek, waktu yang tepat, dan mengalokasikan sumber daya manusia yang sesuai dalam pengerjaan proyek.

\section{Proses Analisis Anggaran dalam Investasi IT}

Untuk meningkatkan keefektifan dan memaksimalkan nilai yang didapat organisasi, maka sebelum melakukan proses investasi harus melakukan analisis terhadap proses yang akan dijalani nantinya. Universitas Bina Nusantara juga melakukan analisis sebelum melakukan investasi dibidang IT. BINUS melakukan analisis pemodelan investasi yang akan dilakukan, agar investasi sesuai dengan tujuan dan kompetensi inti perusahaan, ektraksi kritis faktor keberhasilan dan mendefinisikan bisnis proses yang ada. Investasi IT yang dibangun harus terhubung dengan visi dan strategi BINUS dan menghasilkan keuntungan bagi management. Proses-proses tersebut akan memberikan kontribusi dalam pengambilan keputusan investasi IT.

Dalam memastikan anggaran yang dikeluarkan tidak sia-sia dan tim proyek menyelesaikan sebuah proyek dengan budget yang sudah disetujui, dilakukan manajemen biaya proyek sebagai berikut: (1) cost estimating (perkiraan biaya), BINUS melakukan perkiraan biaya dari resource yang dibutuhkan dalam investasi proyek IT. Dari proses ini akan dihasilkan perkiraan biaya awal 
keseluruhan proyek sampai proyek selesai; (2) cost budgeting (penganggaran biaya), dari perkiraan biaya awal tadi, maka selanjutnya dilakukan alokasi anggaran biaya kepada setiap post/item pekerjaan individu; (3) cost Control (kontrol biaya), BINUS melakukan control terhadap perubahan anggaran, dilakukan pengukuran kinerja proyek, dan dokumentasi terhadap semua perubahan anggaran. Dilakukan juga pengecekan agar perubahan anggaran yang terjadi memang benar-benar perlu dilakukan dan tidak melenceng dari ruang lingkup proyek.

Tipe perkiraan biaya yang paling tepat di BINUS adalah definitive estimate (perkiraan pasti), karena kebanyakan proyek di BINUS masa pembuatannya kurang dari 1 tahun. Hal ini dilakukan untuk menyediakan detail purchasing dan memperkirakan biaya actual. Selanjutnya dibuat rencana pengelolaan biaya, yaitu dokumen yang menggambarkan bagaimana BINUS mengelola jenis-jenis biaya dalam proyek, dalam membuat dokumen ini harus diperhatikan juga waktu dan human resource yang tersedia.

Teknik dan tools yang paling tepat untuk digunakan oleh BINUS dalam membuat perkiraan biaya adalah analogous estimates (top-dowm estimates), karena proyek di BINUS secara garis besar hampir sama antara proyek satu dengan yang lainnya, hanya beda pada proses bisnisnya sesuai dengan tujuan masing-masing proyek.

Dalam proses Cost Control (Kontrol Biaya), BINUS memastikan bahwa biaya yang dikeluarkan sudah sesuai dengan anggaran, dan kalaupun terjadi perubahan biaya, maka hal tersebut memang benar-benar perlu dilakukan dan perubahan yang dilakukan masih sesuai dengan tujuan awal dan scope proyek.

Teknik pengukuran kinerja biaya yang bisa diimplentasikan di BINUS adalah earned value management (EVM), yaitu teknik pengukuran kinerja proyek yang mengintegrasikan lingkup, waktu, dan data biaya. EVM terdiri dari kalkulasi 3 nilai dari tiap aktivitas atau rangkuman aktivitas dari proyek, yaitu Planned Value (PV) yang berisi anggaran, actual cost (AC) yang berisi total biaya, dan earned value (EV) yang berisi perkiraan nilai dari kerja fisikal.

\section{PENUTUP}

Dalam proses investasi IT di BINUS, IT sudah memberikan banyak kontribusi, yaitu menaikkan pendapatan, memberikan efisiensi asset, menghemat biaya, dan memberikan pendapatan berkelanjutan, serta meningkatkan BINUS dalam berinovasi. Terbukti dengan semakin banyaknya masyarakat mengenal BINUS dan percaya pada pendidikan di BINUS. IT dan BINUS adalah 2 komponen yang tidak bisa dipisahkan, bahkan masyarakat Indonesia sudah mengetahui dan mengenal bahwa BINUS adalah universitas dengan teknologi canggih. Brand masyarakat terhadap BINUS adalah universitas dengan teknologi canggih dan up to date dalam proses pembelajarannya.

Investasi IT di BINUS adalah investasi yang sangat berhasil, karena kekuatan IT pada BINUS menjadi daya tarik masyarakat dengan banyaknya mahasiswa intake, dan keunggulan dalam bersaing dengan kompetitornya, serta dengan adanya IT semua proses operasional bisa dilakukan dengan lebih mudah, cepat, efektif, dan efisien. Jadi, investasi IT di BINUS tidak sia-sia, malahan menghasilkan keuntungan yang luar biasa bagi BINUS.

Keberhasilan dalam investasi IT di BINUS karena dilakukannya proses anggaran yang baik dan analisis terhadap pemilihan proyek yang akan dikerjakan. Sehingga proyek yang dibuat benarbenar yang akan berguna dan akan memberikan keuntungan bagi BINUS. 


\section{DAFTAR PUSTAKA}

Gu, B., Xue, L., \& Ray, G. (2008). IT Governance and IT Investment Performance: An Empirical Analysis. Diakses

dari http://www.citeulike.org/pdf_options/user/tilljwinkler/article/8904699?fmt=pdf.

Leem, C. S., Yoon, C. Y., \& Park, S. K. (2004). A Process-Centered IT ROI Analysis with a Case Study. Diakses dari http://www.citeulike.org/pdf_options/user/Warius/article/43846?fmt=pdf.

Maran, C. M. (2009). Measuring return on investment (ROI) in ERP implementation: a management perspective. Tecnia: Journal of Management Studies, 4 (1). Diakses dari http://www.tecnia.in/tiasug/Technia_Journal_April_Sept_09.pdf.

Nagm, F. \& Kautz, K. (2008). The Market Value Impact Of IT Investment Announcements - An Event Study. JITTA: Journal of Information Technology Theory and Application, 9(3), 61-79. Diakses dari http://aisel.aisnet.org/cgi/viewcontent.cgi?article=1031\&context=jitta.

Sakaguchi, T. \& Dibrell, C. C. (1998). Measurement of The Intensity of Global Information Technology Usage: Quantitizing The Value of a Firm's Information Technology. Diakses dari http://www.deepdyve.com/lp/emerald-publishing/measurement-of-the-intensity-of-globalinformation-technology-usage-G49xGQpK3r.

Schwalbe, K. (2007). Information Technology Project Management. Massachusetts: Course Technology. 